\title{
Short-term administration of growth hormone (GH) lowers blood pressure by activating eNOS/nitric oxide (NO)-pathway in male hypophysectomized $(\mathrm{Hx})$ rats
}

\author{
Henrik C Nyström ${ }^{1}$, Natalia Klintland ${ }^{2}$, Kenneth Caidahl2, \\ Göran Bergström ${ }^{1,2}$ and Anna Wickman*1
}

Address: ${ }^{1}$ Department of Physiology, Institute of Physiology \& Pharmacology, The Sahlgrenska Academy, Göteborg University, P.O. Box 432, SE40530 Göteborg, Sweden and 2Department of Clinical Physiology, Sahlgrenska University Hospital/SU, SE-413 45 Göteborg, Sweden

Email: Henrik C Nyström - henrik.nystrom@fysiologi.gu.se; Natalia Klintland - nkharitonova@hotmail.com; Kenneth Caidahl - kencai@ki.se; Göran Bergström - goran.bergstrom@hjl.gu.se; Anna Wickman* - anna.wickman@fysiologi.gu.se

* Corresponding author

Published: 07 November 2005

BMC Physiology 2005, 5:17 doi:10.1 186/1472-6793-5-17

This article is available from: http://www.biomedcentral.com/1472-6793/5/17

(c) 2005 Nyström et al; licensee BioMed Central Ltd.

This is an Open Access article distributed under the terms of the Creative Commons Attribution License (http://creativecommons.org/licenses/by/2.0), which permits unrestricted use, distribution, and reproduction in any medium, provided the original work is properly cited.

\begin{abstract}
Background: The aim of the study was to evaluate the acute and continuous (up to 14 days of treatment) effect of growth hormone $(\mathrm{GH})$ on blood pressure $(\mathrm{BP})$ regulation and to investigate the interplay between $\mathrm{GH}$, nitric oxide (NO) and BP.

In un-supplemented and $\mathrm{GH}$ supplemented hypophysectomized $(\mathrm{Hx})$ male rats as well as intact rats, continuous resting mean arterial blood pressure (MAP) was measured using telemetry. Baroreceptor activity and the influences of NO on BP control were assessed during telemetric measurement. Furthermore, basal plasma and urine nitrate levels and aortic endothelial nitric oxide synthase (eNOS) expression were analysed. Endothelial function as well as vascular structure in the hindquarter vascular bed was estimated using an in vivo constant-flow preparation.

Results: Hypophysectomy was associated with decreased MAP (Hx: $83 \pm 3$ vs Intact: $98 \pm 6$ $\mathrm{mmHg}, \mathrm{p}<0.05)$ and heart rate $(\mathrm{HR})(\mathrm{Hx}: 29 \mathrm{I} \pm 4$ vs Intact: $35 \mathrm{I} \pm 7$ beat $/ \mathrm{min}, \mathrm{p}<0.05)$. Endothelial dysfunction and reduced vasculature mass in the hindquarter vascular bed was found in $\mathrm{Hx}$ rats. GH substitution caused a further transient decrease in MAP and a transient increase in HR (I4\% and $16 \%$ respectively, $\mathrm{p}<0.05$ ). The reduction in MAP appeared to be NO dependent. Aortic eNOS expression was unchanged. GH substitution resulted in an impaired baroreceptor function. Two weeks of $\mathrm{GH}$ treatment did not normalise the BP, vascular structure and the endothelial function in the resistance vessels.
\end{abstract}

Conclusion: $\mathrm{GH}$ substitution seems to have a short lasting effect on lowering blood pressure via activation of the NO-system. An interaction between GH, NO-system and BP regulation can be demonstrated. 


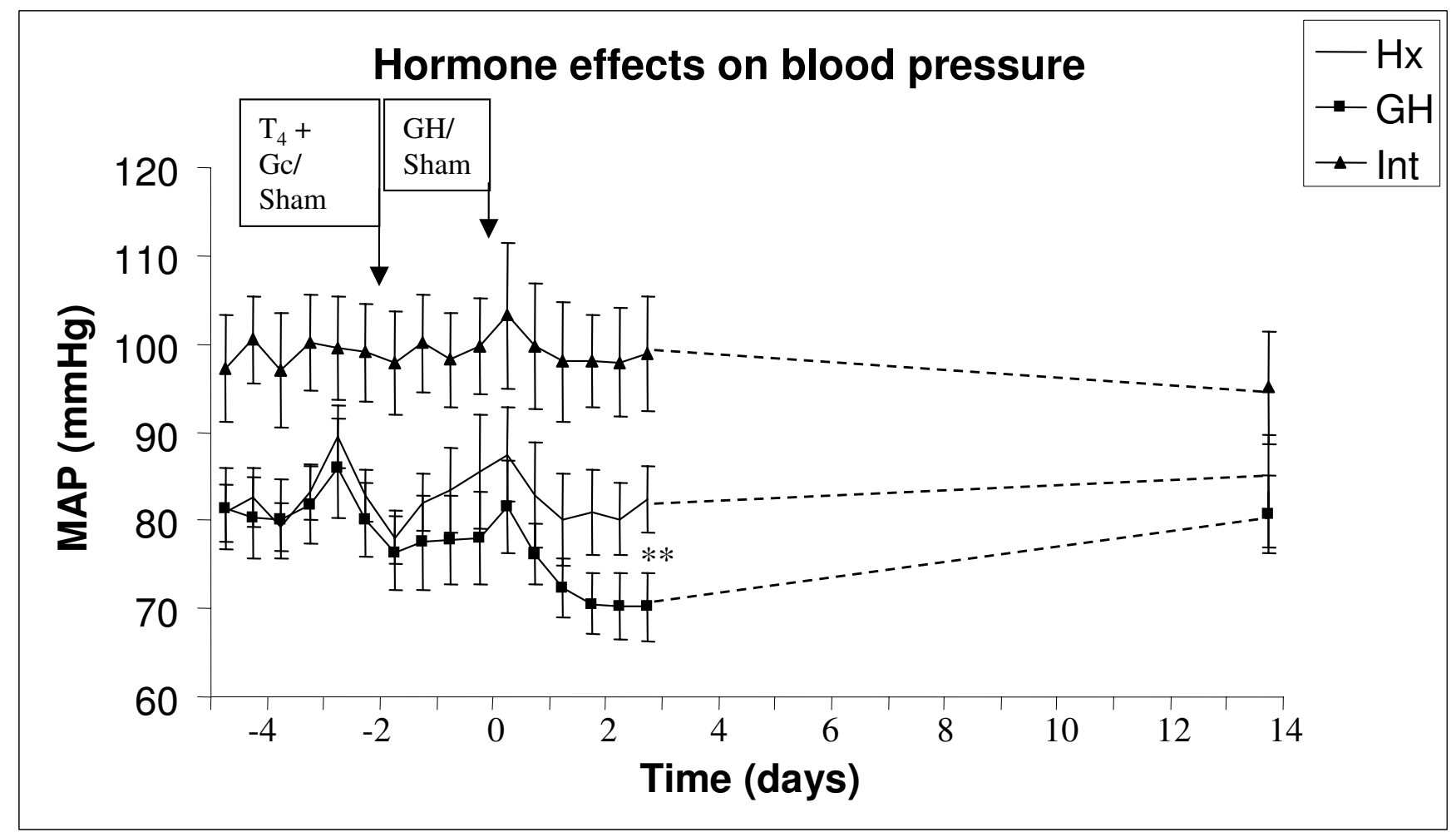

\section{Figure I}

Mean arterial blood pressure (MAP) in hypophysectomized $(\mathrm{Hx}$, solid line), growth hormone supplemented $\mathrm{Hx}(\mathrm{GH}$, solid squares) and in intact rats (solid triangles). The first two days ( -4 to -2$)$ represent non-supplemented basal measurements of MAP in all groups. At day -2 , all $\mathrm{Hx}$ rats received thyroxine and glucocorticoid [T4+GC] treatment with mini-osmotic pumps, whereas the intact rats underwent sham operation. At day zero, the onset of GH treatment (mini-osmotic pumps implantation) was performed in the $\mathrm{GH}$ animals, whereas both intact and $\mathrm{Hx}$ animals underwent sham operation. * indicate $\mathrm{p}<0.05$ between pre- and post-GH treatment in $\mathrm{GH}$ group.

\section{Background}

Adult hypopituitarism and untreated growth hormone (GH) deficiency (GHD) is associated with endothelial dysfunction [1], decreased systemic formation of nitric oxide (NO) [2] and increased risk for cardiovascular morbidity and mortality [3] as compared to the normal population [4]. There are disparate reports on the effect on blood pressure (BP) in this condition; different studies have found normotension, hypotension or hypertension in GHD-patients (for review see [5]). Growth hormone replacement has been shown to reverse many of the adverse cardiovascular risk factors associated with GHD, including decreased systolic and diastolic BP, decreased vascular resistance [6], increased cardiac output (CO), increased heart rate (HR) $[2,6]$, improved endothelial function $[1,7]$ and increased NO formation [2].

Hypophysectomized (Hx) rats express decreased systolic $\mathrm{BP}$ and mean arterial blood pressure (MAP), CO and HR compared with intact rats $[8,9]$. As in human adult GHD, these rats show endothelial dysfunction and impaired vas- cular reactivity $[10,11]$, while aortic endothelial nitric oxide synthase (eNOS) expression is not affected [12]. Furthermore, these rats also display decreased heart weights $[12,13]$, and reduced vasculature mass in the muscle vascular bed suggesting an hypotropic remodelling of the cardiovascular system [13]. One week of GH substitution in Hx rats does not result in a change in systolic BP measured by the tail-cuff technique, whereas HR, heart weight and aortic eNOS expression are increased [12]. The resistance vessels (mesenteric artery) still demonstrate endothelial dysfunction [10]. Previous studies on $\mathrm{BP}$ regulation in $\mathrm{Hx}$ rats $[10,12,13]$ have used less precise techniques to measure BP i.e. tail-cuff technique and therefore showed imprecise GH effect on acute and continuous BP regulation.

In the present study we aimed to investigate the acute and continuous (up to 14 days of treatment) effect of growth hormone substitution on blood pressure regulation. In order to measure the true, unstressed BP, we used a telemetry technique with implantable transmitters. We were 


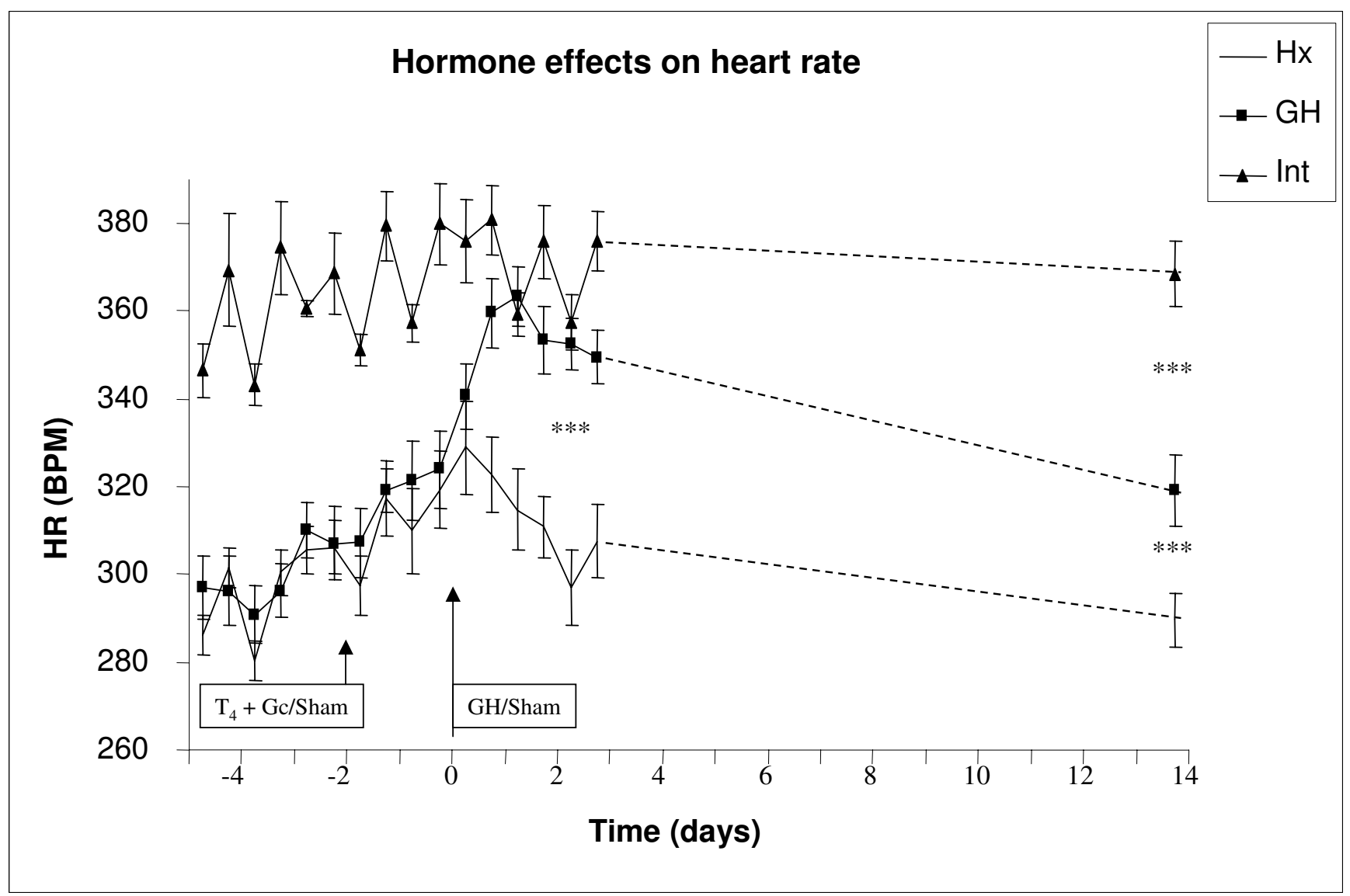

Figure 2

Heart rate (HR) in hypophysectomized (Hx, solid line), growth hormone supplemented $\mathrm{Hx}$ (GH, solid squares) and in intact rats (solid triangles). The first two days $(-4$ to -2$)$ represent non-supplemented basal measurements of HR in all groups. At day -2 , all $\mathrm{Hx}$ rats received thyroxine and glucocorticoid $[T 4+\mathrm{GC}]$ treatment with mini-osmotic pumps, whereas the intact rats underwent sham operation. At day zero, the onset of $\mathrm{GH}$ treatment (mini-osmotic pumps implantation) was performed in the $\mathrm{GH}$ animals, whereas both intact and $\mathrm{Hx}$ animals underwent sham operation. * indicate $\mathrm{p}<0.05$ between pre- and post-GH treatment in $\mathrm{GH}$ group.

also interested in investigating the interplay between $\mathrm{GH}$, NO and BP. In order to do this we used a specific NOS blocker and measured the aortic eNOS expression, basal plasma and urine nitrate levels. In addition, baroreceptor activity was examined both early and late after onset of GH treatment. At the end of the study, endothelial function and the vascular structural properties in the hindquarter were studied using an in vivo constant-flow preparation.

\section{Results}

Growth hormone causes a transient decrease in mean arterial blood pressure and $a$ transient increase in heart rate, Fig I and 2

Hypophysectomy per se, caused a $17 \%$ decrease in MAP and HR before onset of hormonal treatment (MAP; Intact: $98 \pm 6, \mathrm{Hx}: 83 \pm 3, \mathrm{GH}: 81 \pm 5, \mathrm{p}<0.05$ Intact vs $\mathrm{GH}$ or
Hx, Fig 1, HR; Intact: $351 \pm 7$, Hx: $291 \pm 4$, GH: $295 \pm 7$, p $<0.05$ Intact vs GH or Hx, Fig 2). Neither MAP nor HR changed when the Hx rats were treated with $\left[\mathrm{T}_{4}+\mathrm{GC}\right]$ compared with pre-treatment levels or with intact rats (day -2, Fig 1 and 2). Growth hormone caused an immediate drop in MAP by approx $14 \%$ (to $70 \pm 4 \mathrm{mmHg}$, $\mathrm{p}<0.05$ vs $\mathrm{Hx}$, Fig 1) with a concomitant increase in HR by approx. $16 \%$ (to $351 \pm 6$ beat $/ \mathrm{min}, \mathrm{p}<0.05$ vs Hx, Fig 2 ). After 14 days of GH therapy, the MAP returned to pre-treatment levels (day $14=81 \pm 4 \mathrm{mmHg}$, Fig 1), indicating that GH had a transient effect on BP regulation. Similarly, HR returned to pre-treatment levels (pre-treatment $=319 \pm 7$ vs day 14 $=319 \pm 8$ beat $/ \mathrm{min}$, Fig 2). Mean arterial pressure was unchanged in both $\mathrm{Hx}$ and intact rats during the treatment period (Hx: $81 \pm 3$ to $83 \pm 6 \mathrm{mmHg}$, Intact: $98 \pm 6$ to $95 \pm 6 \mathrm{mmHg}$ ). In addition, no change in HR was detected in $\mathrm{Hx}$ and intact rats during the treatment period 


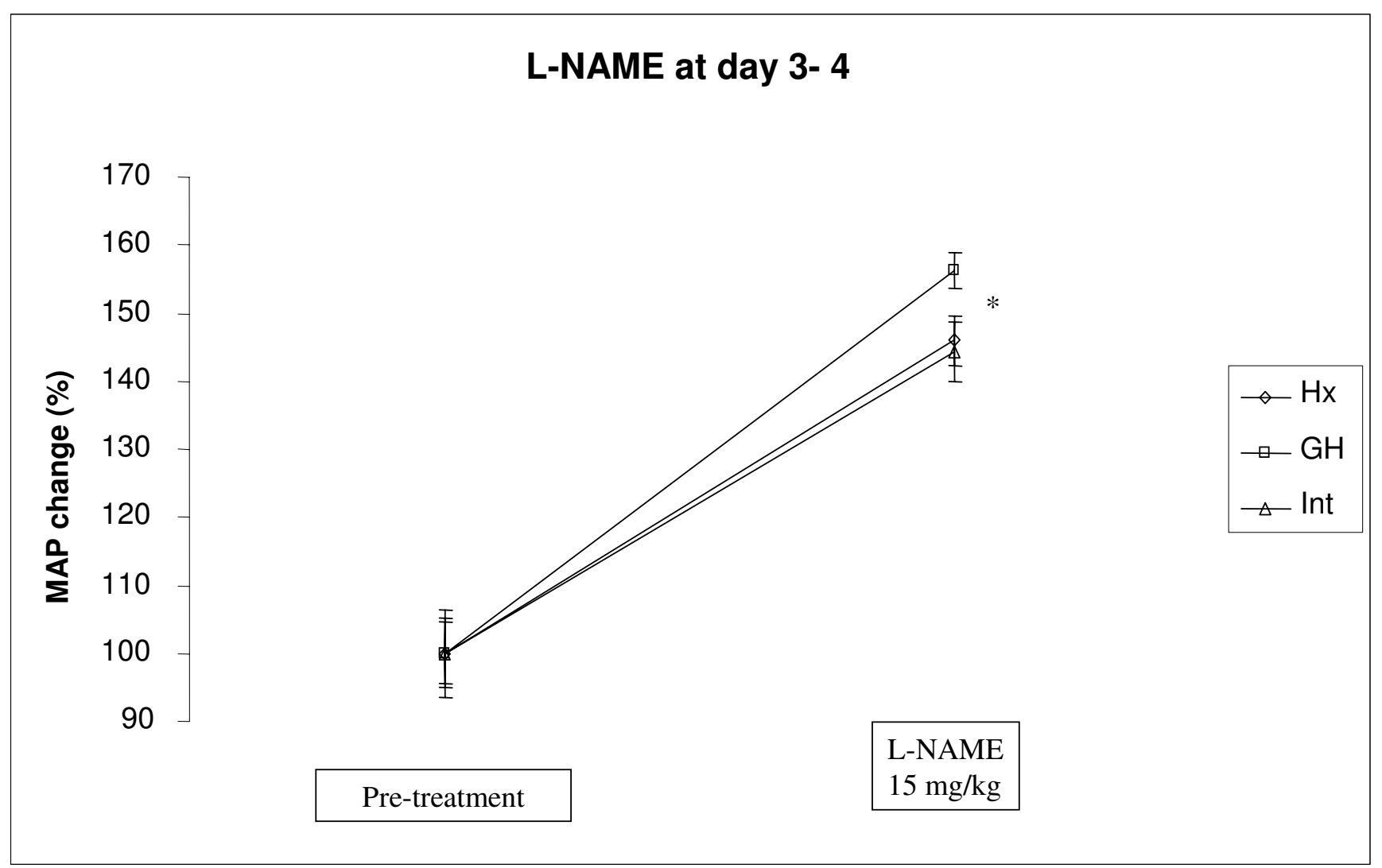

Figure 3

Effect of a single dos of L-NAME (I5 mg/kg, s.c.) on mean arterial blood pressure (MAP) in hypophysectomized (Hx, solid line), growth hormone supplemented $\mathrm{Hx}(\mathrm{GH}$, solid squares) and in intact rats (solid triangles). The $\mathrm{L}$ NAME injection was given early, at day three or four (see in method section for further information) after onset of $\mathrm{GH}$ treatment. *indicates $\mathrm{p}<0.05$ between $\mathrm{GH}$ and intact or $\mathrm{Hx}$ animals.

$(\mathrm{Hx}: 291 \pm 4$ to $290 \pm 6$ beat $/ \mathrm{min}$, Intact: $351 \pm 7$ to $368 \pm$ 7 beat/min). At day 14, the HR, but not MAP, was significantly changed between the groups ( $\mathrm{p}<0.05 \mathrm{Hx}$ vs $\mathrm{GH}, \mathrm{p}$ $<0.05$ GH vs Intact and p $<0.05$ Hx vs Intact).

\section{Growth hormone decreasing effect on blood pressure was NO dependent, Fig 3 and 4 \\ Early L-NAME treatment}

Both intact and $\mathrm{Hx}$ rats had a similar BP response to LNAME with an increase of approx $45 \%$ ( $\mathrm{Hx}$ from $82 \pm 4$ to $120 \pm 7 \mathrm{mmHg}$, Intact from $99 \pm 6$ to $142 \pm 8 \mathrm{mmHg}$, Fig $3)$. Growth hormone treatment caused a significantly greater BP response of approx 56\% (GH from $71 \pm 4$ to $110 \pm 6$ mmHg, $\mathrm{p}<0.05$ vs. Intactand Hx, Fig 3).

\section{Late L-NAME treatment}

There was no difference in the response of MAP to LNAME between the groups (Intact from $91 \pm 6$ to $144 \pm 9$ $\mathrm{mmHg}$, Hx from $76 \pm 5$ to $126 \pm 5 \mathrm{mmHg}$, GH from $74 \pm$ 4 to $120 \pm 9 \mathrm{mmHg}$, Fig 4 ).

\section{Aortic eNOS expression was unaffected after 14 days of GH substitution}

Hypophysectomy per se, had no effect on aortic eNOS protein levels (Intact: $121 \pm 31$ vs $\mathrm{Hx}: 91 \pm 26 \%$ ). There was no significant change in aortic eNOS expression after $\mathrm{GH}$ treatment compared with both $\mathrm{Hx}$ and Intact rats (GH: $110 \pm 16 \%$ ).

\section{Growth hormone effects on basal urine and plasma nitrate and nitrate clearance}

The urine nitrate was lower, but not significantly decreased in the Hx group compared to $\mathrm{GH}$ and intact (Hx: $216.16 \pm 72.23$, Intact: $400.15 \pm 94.65$, GH: $641.1 \pm$ $208.7 \mu \mathrm{M} / \mathrm{ml} / 100 \mathrm{~g}$ BW n.s.). Both Hx and GH rats had significantly higher levels of plasma nitrate compared with intact rats $(\mathrm{Hx}: 79.4 \pm 5.9, \mathrm{GH}: 78.2 \pm 5.7$, Intact: $46.4 \pm 2.3 \mu \mathrm{M}, \mathrm{p}<0.05$ between $\mathrm{Hx}$ and intact and between GH and intact). The nitrate clearance was calculated in all groups, demonstrating that GH had an increased clearance compared with $\mathrm{Hx}$ rats, but similar 


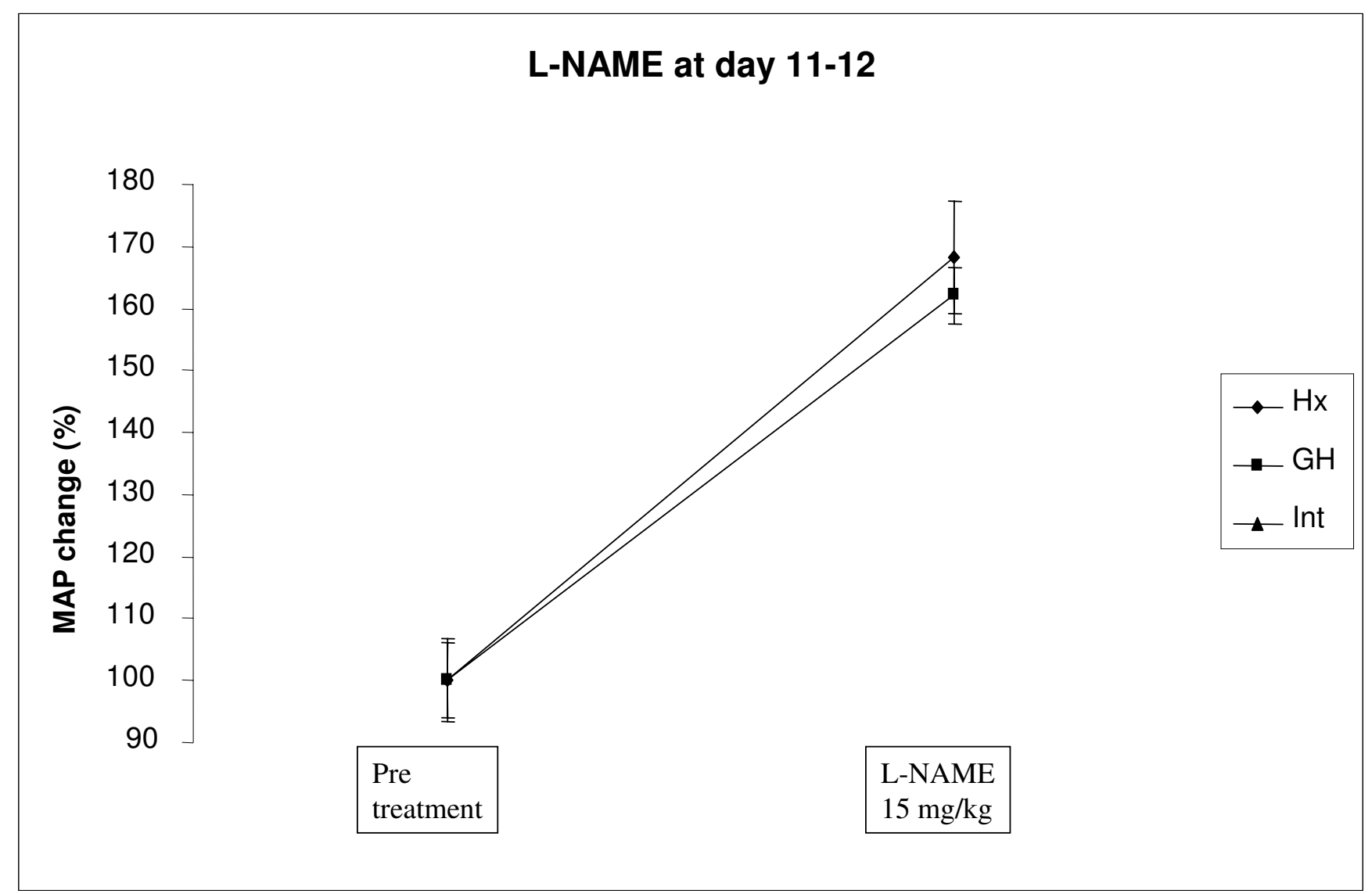

\section{Figure 4}

Effect of a single dos of L-NAME (I $5 \mathrm{mg} / \mathrm{kg}$, s.c.) on mean arterial blood pressure (MAP) in hypophysectomized (Hx, solid line), growth hormone supplemented $\mathrm{Hx}$ (GH, solid squares) and in intact rats (solid triangles). The L NAME injection was given late, at day eleven to twelve (see in method section for further information) after onset of GH treatment.

with intact rats $(\mathrm{Hx}: 1.8 \pm 0.6, \mathrm{GH}: 6.2 \pm 2.0$, Intact: $6.2 \pm$ $1.5 \mu \mathrm{l} / \mathrm{min} / 100 \mathrm{~g}, \mathrm{p}<0.05$ between $\mathrm{Hx}$ and intact and between $\mathrm{GH}$ and intact).

\section{Growth hormone caused a blunted baroreceptor activity,} Fig 5

The baroreceptor activity, tested by phenylephrine, was similar in intact and Hx rats (Intact: $-0.94 \pm 2.29$, Hx: $2.35 \pm 0.69 \mathrm{bpm} / \mathrm{mmHg}$, Fig 5). In contrast, GH resulted in a blunted baroreceptor activity $(0.12 \pm 0.82, \mathrm{p}<0.05$ vs $\mathrm{Hx}$, Fig 5). When the rats were pre-treated with L-NAME, none of the groups differed in baroreceptor activity (Intact: $-2.41 \pm 2.4, \mathrm{Hx}:-2.23 \pm 0.68, \mathrm{GH}:-0.51 \pm 0.40$ $\mathrm{bpm} / \mathrm{mmHg}$.

\section{Growth hormone increases body weight}

The BW of the Hx group did not change over time, indicating a complete hypophysectomy (from arrival to the onset of treatment: Intact: $295 \pm 11$ to $391 \pm 24$ g, Hx: 251 \pm 19 to $225 \pm 13 \mathrm{~g}, \mathrm{GH}: 256 \pm 14$ to $232 \pm 15 \mathrm{~g}, \mathrm{p}<0.05$ between Intact and $\mathrm{Hx}$, Intact and $\mathrm{GH}$ at both time points). After 14 days of treatment, the $\left[\mathrm{T}_{4}+\mathrm{GC}\right]$ group did not change in $\mathrm{BW}$ compared to pre-treated weight $(\mathrm{Hx}$ : $232 \pm 8$ to $232 \pm 7 \mathrm{~g}$ ). The Intact group increased by approx. $2 \%$ in BW during this period $(391 \pm 24$ to $399 \pm$ $28 \mathrm{~g}, \mathrm{~N} . \mathrm{S}$.). The GH group increased in BW by $5 \%$ during the treatment period (from $256 \pm 14$ to $268 \pm 19$ g, p < $0.05)$.

\section{Growth hormone caused a increased plasma IGF-I}

Plasma IGF-I decreased in Hx rats by approx. 85\% compared with Intact rats (Intact: $1098 \pm 46$ vs Hx $164 \pm 27 \mathrm{ng} /$ $\mathrm{ml}, \mathrm{p}<0.05)$. There was a substantial increase in plasma IGF-I after 14 days of GH therapy by approx. 8-fold increase (Hx: $164 \pm 27$ vs GH: $736 \pm 56 \mathrm{ng} / \mathrm{ml}, \mathrm{p}<0.05)$. Growth hormone treated rats displayed a significant decrease in plasma IGF-I compared with intact rats $(\mathrm{p}<$ $0.05)$. 


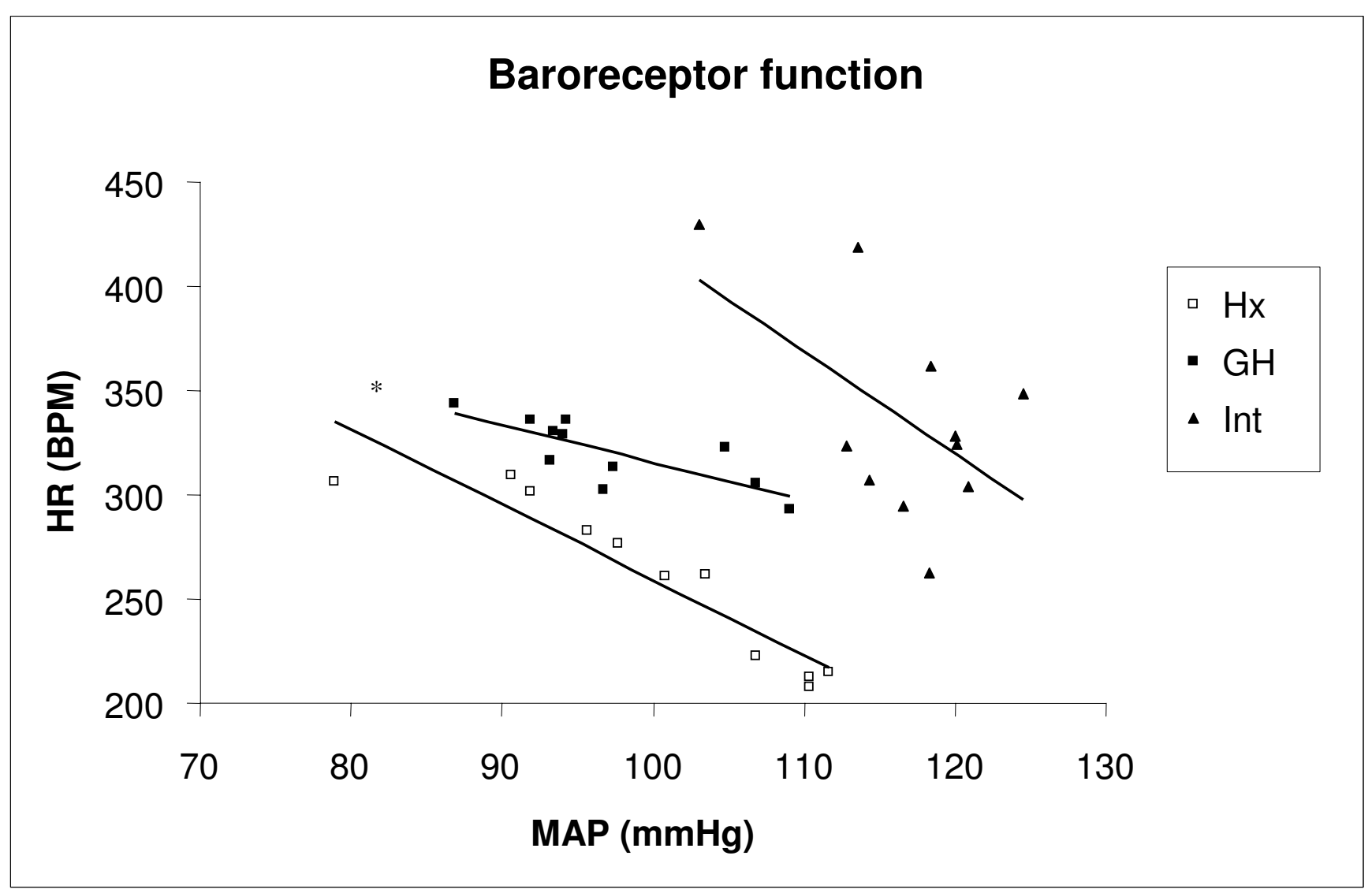

\section{Figure 5}

Baroreceptor activity was tested in hypophysectomized ( $\mathrm{Hx}$, open squares), growth hormone treated $\mathrm{Hx}$ rats (GH, solid squares) and in intact rats (solid triangles). Baroreceptor activity test was performed with a single dose of phenylephrine (4 mg/ $\mathrm{kg}$, s.c.). Mean arterial blood pressure (MAP) and heart rate (HR) were correlated to each other and the k-values were calculated in all groups. *indicate a significant difference of the slope between $\mathrm{Hx}$ and $\mathrm{GH}$ rats.

\section{Growth hormone effect on heart weight and structural parameters of the resistance vessels, Table I and Fig 6}

The relative LV weight was not changed between $\mathrm{Hx}$ and intact animals. Surprisingly, there was a significant loss of weight in the LV after GH therapy by approx. 2\% ( $\mathrm{p}<0.05$ vs Hx rats, Table 1). The RV weight was not changed between the groups (Table 1).

The skeletal muscle vascular bed in Hx rats showed an increased sensitivity (left shift) to administered NA by approx. 22\% compared with intact rats (Table 1), indicating an increased sensitivity of the vascular á-adrenoceptors. Treatment with GH resulted in a normalisation of the NA sensitivity (right shift) (Table 1 ). The perfusion resistance (PR) obtained at maximal dilation was decreased by approx. 19\% in both GH and Hx group compared with intact rats (Intact: $1.94 \pm 0.06, \mathrm{Hx}: 1.16 \pm 0.04, \mathrm{GH}: 1.12$ $\pm 0.08 \mathrm{mmHg} / \mathrm{ml} / \mathrm{min} / 100 \mathrm{~g}$ dry HQ, $\mathrm{p}<0.05$ vs intact and $\mathrm{GH}$ and $\mathrm{Hx}$, Fig 6A). When vasoconstriction was induced by means of NA or with angiotensin II+phenyle- phrine, both Hx and GH group showed approx. 42\% and $40 \%$, respectively, decreased resistance response compared with intact rats (Table 1). Similar resistance changes were obtained in $\mathrm{GH}, \mathrm{Hx}$ and intact rats after maximal constriction was induced by $\mathrm{BaCl}_{2}$ (Intact: $61 \pm 7$, $\mathrm{Hx}: 26$ $\pm 5, \mathrm{GH}: 31 \pm 4 \mathrm{mmHg} / \mathrm{ml} / \mathrm{min} / 100 \mathrm{~g}$ dry HQ, $\mathrm{p}<0.05$ Intact $v$ s $\mathrm{GH}$ and $\mathrm{Hx}$, Fig 6B). The average slope calculated from individual pressure-flow curves, also obtained during full vascular relaxation, showed similar magnitude of structural changes between $\mathrm{Hx}, \mathrm{GH}$ and intact rats (Intact: $0.84 \pm 0.04, \mathrm{Hx}: 0.47 \pm 0.02, \mathrm{GH}: 0.44 \pm 0.03 \mathrm{mmHg} / \mathrm{ml} /$ min/100 g dry HQ, $\mathrm{p}<0.05$ Intact $v$ s GH and Hx, Fig 6C). Both the GH treated and Hx rats showed endothelial dysfunction compared with Intact rats, demonstrated by decreased dilation after a single dose of acetylcholine (Intact: $73 \pm 1 \%$, Hx: $65 \pm 3 \%$, GH: $61 \pm 4 \%$, Fig 6D).

\section{Discussion}

The major findings in this study are; (i) Hypophysectomy per se, caused a decrease in MAP and HR, endothelial dys- 
Table I: Effects of I4 days of administration of thyroxine (T4), glucocorticoids (GC) and growth hormone (GH) were studied in male hypophysectomized $(\mathrm{Hx})$ rats. Intact rats were also used. The parameters that were studied were: body weight (BW), wet hindquarter (HQ weight), dry HQ, oedema, left (LV) and right (RV) ventricular and heart weight (HW) as well on structural properties in the skeletal muscle bed. The perfusion resistance (PR) was calculated as $P R / f l o w(\mathrm{ml} / \mathrm{min}) / 100 \mathrm{~g}$ dry HQ weight for noradrenalin and angiotensin II (Ang II)/phenylephrine (Phe) responses. The ED-50 value demonstrates the half-maximal effect of the effective noradrenalin dose, demonstrating the adreno-receptor sensitivity. Maximal noradrenaline and Ang and Phe responses reflect the average medial bulk of contractile tissues. Values are expressed as MEAN \pm SE. §denotes that both protocol I and 2 are included. *denotes that the number in the groups are changed, intact group $n=8, \mathrm{Hx}$-group $n=6$ and $\mathrm{GH}$ group $n=6$. adenotes $p<0.05$ vs. intact, bdenotes $\mathrm{p}<0.05$ vs. Hx-[T4+GC].

\begin{tabular}{|c|c|c|c|}
\hline & Intact & $\mathrm{Hx}\left[\mathrm{T}_{4}+\mathrm{GC}\right]$ & $\mathbf{H x} \mathbf{G H}+\left[\mathrm{T}_{4}+\mathbf{G C}\right]$ \\
\hline $\mathbf{N}$ & 14 & 12 & 12 \\
\hline BW (g) & $402 \pm 5$ & $222 \pm 3^{a}$ & $265 \pm 5^{\mathrm{a}, \mathrm{b}}$ \\
\hline Wet HQ weight (g/100 g BW) & $44.4 \pm 1.0$ & $43.3 \pm 3.1$ & $41.7 \pm 1.7^{a}$ \\
\hline Dry HQ weight (g/100 g BW) & $21.6 \pm 0.3$ & $18.4 \pm 0.6^{\mathrm{a}}$ & $15.6 \pm 1.7 \mathrm{a}, \mathrm{b}$ \\
\hline Oedema (\%) & $51 \pm 1$ & $57 \pm 2$ & $62 \pm 2^{a, b}$ \\
\hline LV weight $(\mathrm{mg} / 100 \mathrm{~g} \mathrm{BW}) \S$ & $161.6 \pm 12.6$ & $164.4 \pm 16.2$ & $158.5 \pm 14.7^{b}$ \\
\hline RV weight (mg/l $00 \mathrm{~g} \mathrm{BW}) \S$ & $41.9 \pm 9.9$ & $42.1 \pm 9.8$ & $39.9 \pm 9.9$ \\
\hline $\mathrm{HW}(\mathrm{mg} / 100 \mathrm{~g} \mathrm{BW})^{\S}$ & $203.3 \pm 15.0$ & $206.5 \pm 20.3$ & $186.4 \pm 29.3^{\mathrm{a}, \mathrm{b}}$ \\
\hline ED 50 value of noradrenalin & $0.593 \pm 0.066$ & $0.463 \pm 0.05^{\mathrm{a}}$ & $0.584 \pm 0.074 b$ \\
\hline $\begin{array}{l}\text { PR Noradrenalin response } \\
(\mathrm{mmHg} / \mathrm{ml} / \mathrm{min} / 100 \mathrm{~g} \text { dry HQ) }\end{array}$ & $23.64 \pm 2.4$ & $13.8 \pm 0.8^{a}$ & $13.8 \pm 1.4^{\mathrm{a}}$ \\
\hline $\begin{array}{l}\text { PR Ang II + Phe response } \\
(\mathrm{mmHg} / \mathrm{ml} / \mathrm{min} / 100 \mathrm{~g} \text { dry } \\
\text { HQ)* }\end{array}$ & $33 \pm 7$ & $17 \pm 2$ & $22 \pm 5$ \\
\hline
\end{tabular}

Values are expressed as MEAN \pm SE. §denotes that animals from both protocol I and 2 are included. *denotes that the number in the groups are changed, intact group $n=8, \mathrm{Hx}$-group $n=6$ and $G H$ group $n=6$. adenotes $p<0.05$ vs. intact, bdenotes $p<0.05$ vs. $H x-\left[T_{4}+G C\right]$

function and reduced vasculature mass in the hindquarter vascular bed. (ii) Supplementation with $\left[\mathrm{T}_{4}+\mathrm{GC}\right]$ did not change any of the studied parameters. (iii) GH substitution resulted in a transient decrease in MAP and a transient increase in HR. (iv) GH substituted rats had an increased MAP response after administration of early LNAME compared with intact and Hx rats, indicating a transient activation of NO by GH. (v) Long-term GH treatment resulted in an impaired baroreceptor activity. (vi) 14 days of GH therapy to $\mathrm{Hx}$ rats neither improved the endothelial function nor restored the vascular structure. Taken together, GH substitution seems to have a short lasting effect on lowering blood pressure via activation of the NO-system. The transient increase in HR is most likely mediated by a baroreceptor activation. These data also suggest that a longer period of GH therapy is required to improve endothelial function and to restore the morphology of the vasculature. Finally, there is interplay between $\mathrm{GH}, \mathrm{NO}$-system and blood pressure regulation.

\section{The effect of GH on blood pressure}

Growth hormone therapy to Hx rats caused an immediate and transient decrease in MAP. This reduction in MAP appears to be NO-dependent since L-NAME treatment caused a greater MAP response than it did in both $\mathrm{Hx}$ and intact rats. We speculate that this finding may reflect an increase in eNOS activity and/or expression, resulting in enhanced NO bioavailability. This may in turn lead to decreased total peripheral resistance $[6,14]$, resulting in reduced MAP. Growth hormone and IGF-I has been shown to increase eNOS in vitro [15] as well as to increase eNOS expression [12] and NO formation [2]in vivo.

It has been suggested that GH treatment can be associated with an increase in extra cellular volume (ECV) [16-18]. An increased volume load may theoretically lead to an increase in BP. However, a previous published study showed that increased body sodium concentration and increased ECV after GH substitution to GHD patients were not associated with an increase in BP [18]. Taken together, this suggests that the load of ECV seems to be of minor importance for the BP regulation at least in GH treated GHD patients.

The GH activated NO-dependent decrease in MAP appears to be transient since 12 days of GH therapy, results in a similar increase in MAP after a single dose of L-NAME as it did in both intact and Hx animals. This result is supported by unchanged aortic eNOS expression in all groups and the return of MAP to pre-treatment levels in GH treated rats. The present study showed increases of urine nitrate after 12 days of GH treatment, which may suggest that there is still some GH stimulated NO production left, although this increase appears to be of minor importance for the BP regulation. The level of MAP in GH rats did not return to the level in intact rats. It is possible that the observed reduction of the resistance vessels mass in the hindquarters vascular bed could be the explanation. Folkow et al [13] have shown that 6 weeks of treatment with both $\mathrm{GH}$ and $\mathrm{T}_{4}$ results in normalisation of $\mathrm{BP}$ as well 
A

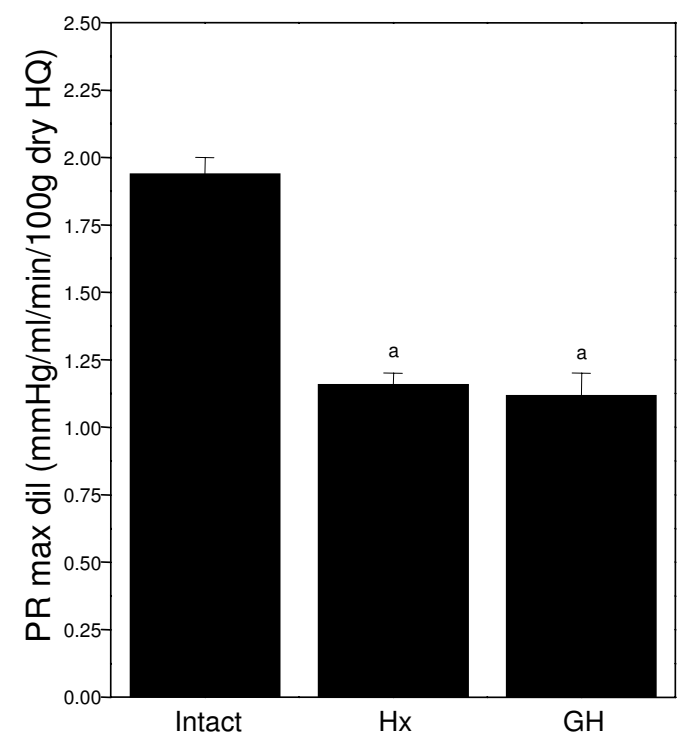

C

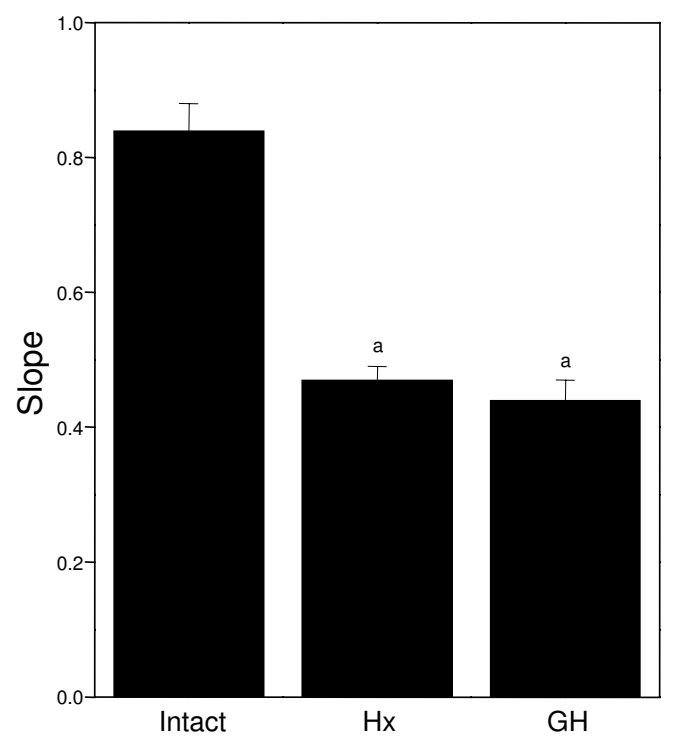

B

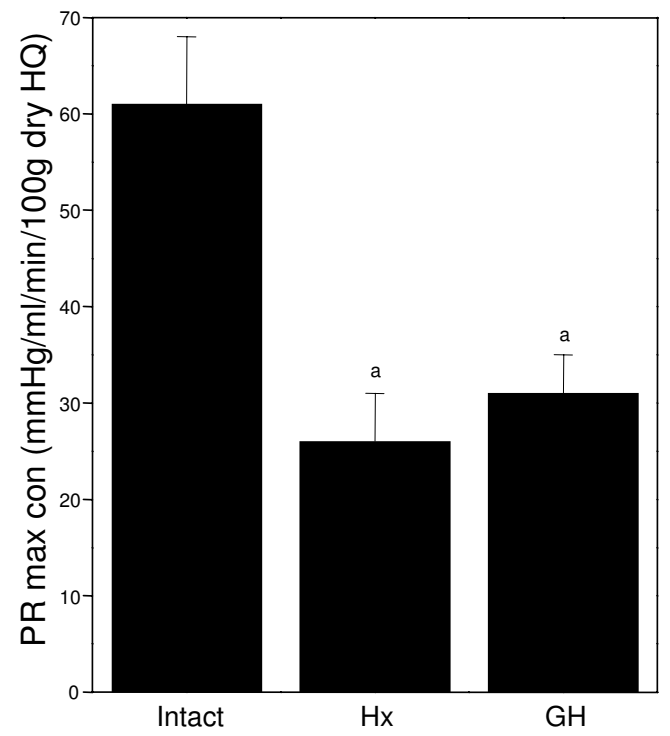

D

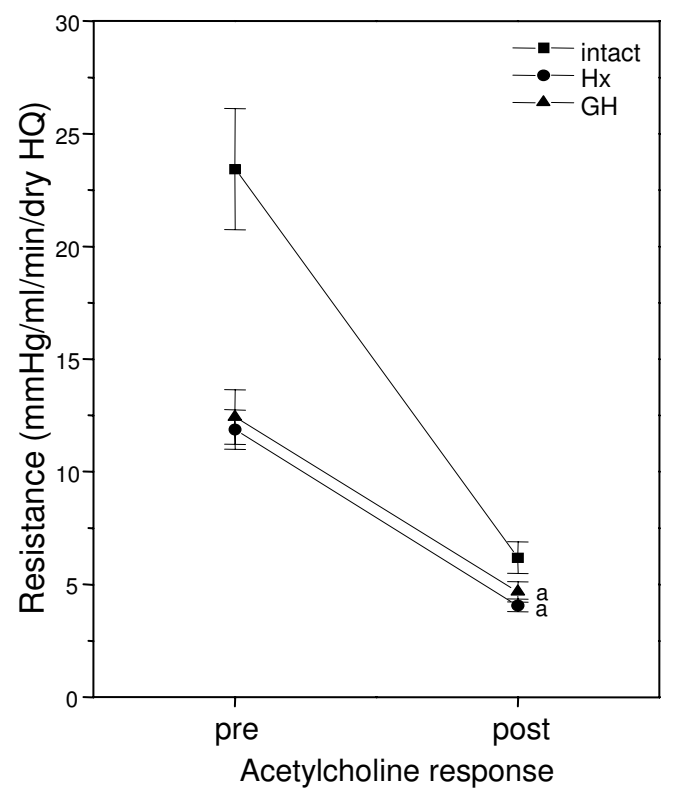

Figure 6

Graphs A-C showing the effect of hypophysectomy $(\mathrm{Hx})$ and 14 days of growth hormone substitution to $\mathrm{Hx}$ rats (GH) on structural properties and acetylcholine response (D) in the skeletal vascular bed. (A) Graphs showing the perfusion resistance (PR) at maximal dilation (max dil), reflecting the average internal radius of the skeletal vasculature. (B) Graph showing the PR at maximal constriction (max con) obtained by barium chloride, reflecting average medial bulk of contractile tissue. (C) Graph showing slope, calculated by linear regression from individual pressure-flow curves during perfusion at maximal dilation. (D) Linear graph showing the resistance pre (during maximal noradrenaline constriction) and post (after a single dose of acetylcholine) in the skeletal vascular bed, reflecting the endothelial function. *indicate $\mathrm{p}<0.05$ between intact and $\mathrm{GH}$ or $\mathrm{Hx}$ rats. 
as an enhanced vascular mass in the hindquarter vascular bed. In GH over-expressed mice, increased vascular mass has also been described $[19,20]$. These mice displayed either hypertension [19] or normotension [20]. Thus, it seems that a longer supplementation period is required to give an effect of vascular morphology on the resistance vessels as well as to normalise BP. However, hGH treatment to Hx rats for longer periods than two to three weeks have been reported to result in antibodies against GH [21]. Guided by this information, we decided to limit the study to two weeks.

\section{Growth hormone effect on heart rate and the baroreceptor activity}

In the present study, GH substitution results in an immediate and transient increase in HR, which is partly in accordance with other studies $[2,6]$. This direct effect in HR can probably be explained by an increased sympathetic activity that could originate from increased firing of baroreceptors in response to decreased MAP. Two weeks of GH therapy resulted in a normalisation of HR. This transient change in HR might be explained by deactivation of baroreceptors due to increased BP. After twelve days of GH therapy, baroreceptor activity was blunted. The blunted effect of the baroreceptors can most likely be explained in two ways; by loss of structure or by "resetting". Both GH and Hx rats showed reduced vasculature mass in the hindquarter vascular bed, but only GH treated rats exhibit impaired function of the baroreceptors, suggesting that the blunted function of the baroreceptors could not be due to loss of structure in the baroreceptors in GH rats. Therefore, our data suggest that the impaired function of the baroreceptors seems to be related to "resetting". It has been suggested that NO appears to act as a sympatholytic agent to modulate the central sympathetic outflow [22]. The impaired baroreceptor activity appears not to be NO-dependent, since the blunted effect of the baroreceptors was unchanged after L-NAME treatment.

\section{Growth hormone effect on adreno-receptor sensitivity and endothelial function}

Growth hormone treated Hx rats showed a right shift and/ or normalisation of the noradrenalin $\mathrm{ED}_{50}$ value in the hindquarters vascular bed, which is in accordance with other studies $[11,13,19]$. Long-term GH replacement in GHD patients has been shown to decrease sympathetic activity to the muscular vascular bed [23], whereas heart rate variability displays increased ratio of sympato-vagal tone, decreased vagal tone and increased sympathetic tone [24]. This might suggest that the rightward shift and/ or normalisation of the noradrenalin $\mathrm{ED}_{50}$ value in the hindquarter vascular bed is caused by increased sympathetic tone and changed ratio between the sympato-vagal and the vagal tone.
It is well known that GHD patients exhibit endothelial dysfunction $[1,25]$. This phenomenon has been detected in both conduit [11] and resistance vessels in Hx rats [10]. Accordingly, in this study the resistance vessels in the hindquarter vascular bed also exhibit endothelial dysfunction in Hx rats. Neither one week [10] nor two weeks of GH therapy resulted in improved endothelial function in the resistance vessels. In contrast, both GH supplemented GHD patients [7] as well as GH treated Hx rats [11] show improved endothelial function in the conduit vessels. This suggests that longer treatment is required to enhance the endothelial function in the resistance vessels.

\section{Conclusion}

Hypophysectomy per se, is associated with decreased MAP, HR and loss of vascular structure. Growth hormone substitution to $\mathrm{Hx}$ rats results in a transient decrease in MAP and a transient increase in HR. This transient decrease of MAP was NO dependent. Growth hormone treatment caused an impaired baroreceptor activity. Two weeks of GH therapy neither improved the endothelial function nor restored vascular parameters. To summarize, GH substitution seems to have a short lasting effect on lowering blood pressure via activation of the NO-system. These data also suggest that a longer period of GH therapy is required to improve endothelial function and to restore the morphology of the vasculature. Finally, there is an interplay between GH, blood pressure and NO-system.

\section{Methods \\ Animals}

Male Wistar rats were obtained from M\&B (Ejby, Denmark). The rats underwent hypophysectomy at approximately eight weeks of age (approx. 280-300 g) at M\&B one week prior arrival to our facility. The protocol conformed to guidelines on the conduct of animal experiments issued by the Swedish National Board for Laboratory Animals and was approved by the Ethics Committee for Animal Experiments at Göteborg University. The animals were housed at constant temperature $\left(20^{\circ} \mathrm{C}\right)$ at a relative humidity of 50-60\%. A $12 \mathrm{~h}$ dark/light cycle was maintained with lights on/off at $07.00 \mathrm{AM}$ to 7.00 PM. The rats had free access to standard pellet chow and tap water throughout the study. All rats were acclimatized for one week before the onset of the experiment. Body weight (BW) was measured throughout the study once a week.

\section{Experimental protocol}

Two different experimental protocols were used.

\section{Substitution therapy}

In both protocol 1 and 2 (see below), all Hx rats received thyroxine $\left(\mathrm{T}_{4}, 20 \mu \mathrm{g} / \mathrm{kg} /\right.$ day) and glucocorticoid (GC, 400 $\mu \mathrm{g} / \mathrm{kg} /$ day) $\left(\left[\mathrm{T}_{4}+\mathrm{GC}\right]\right)$ treatment by mini-osmotic pumps 
s.c. (model 2004, Alza Pharmaceuticals, Palo Alto, CA, USA). After two days of $\left[\mathrm{T}_{4}+\mathrm{GC}\right]$ treatment, the Hx rats were divided into two groups of which one was treated with GH ( $1 \mathrm{mg} / \mathrm{kg} /$ day) by a second mini-osmotic pump s.c. (2ML2) for 14 days.

\section{Protocol I}

Hypophysectomized rats and intact controls were equipped with telemetry transmitters for measurement of conscious unrestrained MAP and HR for 18 days (Intact $\mathrm{n}$ $=5, \mathrm{Hx} \mathrm{n}=8$, and GH $\mathrm{n}=5$ ). MAP and HR were measured two days before onset of treatment (Day - 4 to -2) and continued throughout the start of substitution with $\left[\mathrm{T}_{4}+\mathrm{GC}\right]$ (Day -1 to 0) and treatment with GH (Day 1-14). In addition to these baseline measurements, two different experiments were performed; 1 ) the activity of the NO system was assessed by acute administration of L-NAME (early, Day 3-4) and (late, Day 11-12), 2) baroreceptor activity was assessed by acute administration of phenylephrine (Day 11-12). Two days of baseline measurements were recorded before onset of these two experiments. At the end of the 14 day protocol, rats were anesthetized, sacrificed and blood and tissues samples were taken for further analyses.

\section{Protocol 2}

Rats in the second protocol were treated identically as in protocol 1, except that we did not implant telemetry transmitters (Intact $\mathrm{n}=14, \mathrm{Hx} \mathrm{n}=12$, and GH $\mathrm{n}=12$ ). In this protocol, two different experiments were performed; 1) plasma and urine nitrate concentrations were measured (Day 10-12), 2) at the end of the 14 day protocol, vascular structure as well as endothelial function in the hindquarter vascular bed was assessed using an in vivo constant-flow preparation.

\section{Experimental procedures}

Implantation of radio-telemetric implants

During the high dose substitution therapy (see below), a radio telemetric transducer catheter (o.d. $0.76 \mathrm{~mm}$, Data Science International, Inc, St. Paul, MN, USA) was implanted into the lower aorta and glued into position (3 $M$ Vetbond $^{\mathrm{TM}}, 3 \mathrm{M}$ Animal Care Products, St Paul, MN, USA) in Hx ( $\mathrm{n}=13)$ and control $(\mathrm{n}=5)$ rats. Rats were anaesthetized using Ketalar:Rompun (39:5 mg/kg) and isoflurane (Baxter Healthcare, Chicago, MI, USA). The catheter tip was placed at least $1 \mathrm{~cm}$ below the renal arteries. The transmitter (TA11PA-C40) was secured to the abdominal wall and the abdomen closed with sutures. After four weeks of recovery and without hormonal supplementation, the animal in its home cage was placed on a receiver plate and the signal collected using the Dataquest LabPRO Acquisition System (Ver. 3.0, Data Sciences international, Inc, St. Paul, MN, USA). The following sampling parameters were used; sampling frequency
$500 \mathrm{~Hz}$, sample duration $15 \mathrm{sec}$, save period $5 \mathrm{~min}$. The mean arterial signal was corrected for electronic offset, the average of one measurement outside the animal before and after implantation.

High dose substitution therapy to improve surgical survival To be able to perform surgery on the vulnerable Hx rats, high-dose steroid therapy and salt $(\mathrm{NaCl})$ enriched diet was given before and after surgery according to the following protocol. For five days all rats ( $\mathrm{Hx}$ and intact rats) had free access to normal tap water and dexamethasone in tap water (orally, $1.5 \mathrm{mg} / \mathrm{l}$ ). Rats also received standard pelletand salt pellet chow $(248 \mathrm{mmol} / 100 \mathrm{~g}$, Lactamin, Vadstena, Sweden). The rats were also treated with glucocorticoid at day $1: 2 \mathrm{mg} / \mathrm{kg} \times 2$, day $2: 2 \mathrm{mg} / \mathrm{kg} \times 3$, day 3: (day of surgery): $2 \mathrm{mg} / \mathrm{kg} \times 4$, day $4: 2 \mathrm{mg} / \mathrm{kg} \times 3$ and day 5: 2 $\mathrm{mg} / \mathrm{kg} \times 2$ (s.c.). This high dose regime was washed out during the following four weeks before onset of the experiment. During this period the rats received no hormonal treatment, but had free access to salt pellet and standard pellet chow. Using this regime $75 \%$ of $\mathrm{Hx}$ animals survived the surgical procedure.

\section{NO dependency protocol}

To test if the NO system was involved in the GH-dependent BP regulation, a NOS antagonist (L-NAME $15 \mathrm{mg} / \mathrm{kg}$, s.c.) was given during two occasions, early (day 3-4) and late (day 11-12). Saline was used as a control and given in an equal volume $(0.1 \mathrm{ml} / \mathrm{kg}$, s.c. $)$. L-NAME and saline were given in randomized order.

\section{Test of baroreceptor activity}

The baroreceptor activity was tested by using phenylephrine $(300 \mu \mathrm{g} / \mathrm{kg}$, s.c.) after pre-treatment with $\mathrm{NaCl}$ or L-NAME at day 11-12. Three hours after late L-NAME or saline were given; all rats received a single dose of phenylephrine to generate a slow gradual increase in MAP and a corresponding baroreceptor elicited decrease in HR within 60 seconds. L-NAME and $\mathrm{NaCl}$ were given in randomized order. To determine the optimal dose of phenylephrine, a dose response curve was established in separate experiments (data not shown).

\section{End of experiment}

On day 13-14 the rats were allowed to recover and baseline measurements were performed. At day 14, the rats were anesthetized using isoflurane and decapitated. Blood samples were taken for IGF-I analysis. The heart and the aorta were quickly excised. The heart was separated into left (LV) (including septum), and right ventricles (RV) and weighed. The aorta was trimmed free of fat and adherent tissues, frozen in liquid nitrogen and stored at $-80^{\circ} \mathrm{C}$ for further analysis. 


\section{Measurements of IGF-I}

In randomly selected plasma samples from protocol 1, the plasma IGF-I content was analyzed by a commercial RIA kit (Mediagnost, Reutlingen, Germany) in intact rats ( $\mathrm{n}=$ $3)$, Hx rats $(n=5)$ and in GH $(n=5)$ treated rats [12].

\section{Immunoblotting}

Immunoblotting and protein extraction techniques have previously been described [12]. Briefly, protein was extracted from the aorta from intact rats $(n=5), H x$ rats $(n$ $=8)$ and GH $(n=5)$ treated Hx rats. The total protein concentration was determined by a commercial protein assay (Bio-Rad, Hercules, CA, USA). $25 \mu \mathrm{g}$ of aorta and liver of total proteins were loaded in each lane on gels $(10 \%$ $\mathrm{NuPAGE}^{\circledR}$ Bis-Tris gels; Novex, San Diego, CA, USA). The gels were run for 90 minutes at constant voltage $(150 \mathrm{~V})$. Molecular weight standards (See Blue ${ }^{\circledR}$; Novex, San Diego, CA, USA) were used on each gel. The proteins were transferred to a polyvinyldifluoride (PVDF) membrane (Amersham, Buckinghamshire, UK). The membranes were incubated with a mouse monoclonal antibody against eNOS (dilution 1:1,000; Transduction Laboratories, Lexington, KY, USA). Immunoreactive protein was visualized by chemiluminescence using an alkaline phosphataseconjugated secondary antibody (dilution 1:30,000; Sigma, St. Louis, MO, USA) and CDP-Star ${ }^{\circledR}$ (Tropix, Bredford, MA, USA) as a substrate. The membranes were exposed to ECL film (Amersham, Buckinghamshire, UK) at room temperature for 1-5 minutes and the films were subsequently developed. Semi quantitative measurements of proteins from the immunoblots were made by densitometry (Fluor- $S^{\mathrm{TM}}$ Multimager, Quantity One ver. 4.1.0, Bio-Rad, Hercules, CA, USA). The optical density (OD) of each band was measured. Lane containing extract of liver was used as a reference on each gel.

\section{Nitrate measurements}

The animals were housed individually in metabolic cages. During the first day of measurement, the rats had free access to tap water and standard pellet chow. During the second and the third day in the metabolic cages, fasting was induced in the animals over night with free access to distillate water. This was in order to avoid interference of food and water on the nitrate measurement [26]. Water intake, urine volume and BW were measured. During the last day of measurements, the urine was collected for 24 hours, weighed and frozen for further nitrate analysis. At the end of the protocol, a blood sample of approximately $200 \mu \mathrm{l}$ was drawn from the tail vein. The whole blood was centrifuged and plasma was collected and frozen for further analysis.

\section{Plasma and urine nitrate analyses}

Plasma and urine samples were analyzed for total nitrate concentration using a gas chromatography/mass spectro- metric method as previously described [27]. Briefly, after the samples had been prepared, the samples were injected into a Varian 3400 gas chromatograph equipped with a 30 m BPX-5 capillary column operated with a temperature program $\left(60-240^{\circ} \mathrm{C}\right)$. A Varian Saturn II mass spectrometer served as detector operating in the positive ion/chemical ionization mode using methane as the reactant gas and selective monitoring of mass equivalent m/z 124 for endogenous nitrate and mass equivalent $\mathrm{m} / \mathrm{z} 125$ for the ${ }_{15} \mathrm{~N}$-labelled internal standard. Basal urine and plasma nitrate concentrations and nitrate clearance were calculated.

\section{Hemodynamic analysis of resistance-vessel design}

The structural characteristics of the skeletal muscle vasculature were analysed hemodynamically using a method which has been described in detail previously [13]. In brief, the isolated hind limbs of randomly treated and untreated rats were perfused in pairs via an aortic cannula. The perfusate consisted of an oxygenated 2\% dextranTyrode solution, to which $0.5 \%$ bovine serum albumin (Sigma Chemicals, St Louis, MISS, USA) had been added. Perfusion pressure was measured via the cannulated tail artery. The hind limb vascular bed was initially maximally dilated by repeated injections of papaverine $(3 \mathrm{mg}$ totally), using constant flow of $10 \mathrm{ml} / 100 \mathrm{~g}$ hind limbs. Pressure-flow curves during maximal dilatation were constructed by altering the speed of the perfusion pump. During this constant flow condition, noradrenalin (NA) in increasing concentrations was added to the perfusate (20$64 \mu \mathrm{g})$. At maximal NA constriction, an injection of acetylcholine $(0.01 \mathrm{mg}$, the correct dose was tested out by dose response curves, data not shown) was given. Finally, angiotensin II (200 ng), phenylephrine (4 mg) and $\mathrm{BaCl}_{2}$ (150 $\mathrm{mg}$ ) were injected. Noradrenalin dose-resistance curves were constructed of hind limb vascular beds, and the ED 50 value was calculated. After the experiment, the hindquarters were dried at $70^{\circ} \mathrm{C}$ for $48 \mathrm{~h}$ and weighed. The dry weight of the HQ was used to standardize the calculation of the hemodynamic parameters.

\section{Hormones, solutions and drugs}

The following hormones were used; Thyroxine $\left(\mathrm{T}_{4}\right.$, L-thyroxine; Nycomed, Oslo, Norway); Glucocorticoid (GC, cortisol phosphate; Solu-Cortef, Upjohn, Puurs, Belgium); human Growth hormone (hGH, Pharmacia, Stockholm, Sweden). Thyroxine, glucocorticoids and hGH were dissolved in $0.9 \% \mathrm{NaCl}$.

The composition (in $\mathrm{mM}$ ) of the $2 \%$ dextran Tyrode solution used in the infusion experiments was $\mathrm{Na}^{+} 148.0, \mathrm{Cl}^{-}$ 133.4, $\mathrm{K}+4.3, \mathrm{Ca}^{2+} 2.5, \mathrm{Mg}^{2+} 0.8, \mathrm{HCO}_{3} 25, \mathrm{H}_{2} \mathrm{PO}_{4}$ 0.5, Dglucose 5.6. 
The following drugs were used: acetylcholine (Sigma); Angiotensin II (Sigma); Phenylephrine (Sigma); Noradrenalin (Sigma); N $\omega$-nitro-L-arginine methyl ester (L-NAME, Sigma); Dexamethasone (Sigma); Papaverine (Sigma).

\section{Statistical analysis}

Values are expressed as MEAN \pm SE. Statistical analyses of BW, plasma IGF-I, eNOS expression, basal urine and plasma nitrate and nitrate clearance, all HQ-data, BP and HR comparisons between the groups and percentages changes after L-NAME treatment were performed by oneway ANOVA followed by Tukey's as a post-hoc test. Hormonal effects on the BP and the HR was calculated by using paired t-test of mean of $24 \mathrm{~h}$ before onset of treatment compared to mean of $24 \mathrm{~h}$ after onset of treatment. L-NAME percentage effect on BP was calculated by comparing 10 values pre-treatment and 10 values post-treatment. Individual $\mathrm{k}$-values was calculated when barorecteptor activity was studied.

\section{Authors' contributions}

HCN: participated in the design of the study, performed some statistical analysis, acquisition of data, analysis and interpretation of data, been involved in the drafting of the manuscript

\section{NK: carried out the nitrate measurements}

KC: involved in the drafting of the manuscript

GB: participated in the design of the study, involved in the drafting of the manuscript

AW: made substantial contribution to concept and design, analysis and interpretation of data, performed statistical analysis, acquisition of data, drafting the manuscript

\section{All authors read and approved the final manuscript}

\section{Acknowledgements}

The critical review of the manuscript by Dr. Yrsa Bergmann Sverrisdottir is highly appreciated. The authors thank Mrs Gunnel Andersson for excellent help with the telemetric probe implantation. This study was supported by the Swedish Research council (GB; 12 580, KC; 14 23I), the Swedish National Heart and Lung foundation (GB, KC), the memory of Lars Hierta $(A W)$, King Gustaf V:s and Queen Victoria foundation (AW), the Emelle foundation (AW), the Swedish Hypertension Society (AW, HN), the Swedish Society of Medicine (AW), the foundation of Tore Nilsson for Medical Research (AW), the foundation of Västra Götalands Regionen (KC) and the foundation of Eva and Oscar Ahrén (HN). The Swedish Heart and Lung foundation and SWEGENE contributed to the post-doctoral position of Anna Wickman.

\section{References}

I. Capaldo B, Guardasole V, Pardo F, Matarazzo M, Di Rella F, Numis F, Merola B, Longobardi S, Sacca L: Abnormal vascular reactivity in growth hormone deficiency. Circulation 200I, 103:520-524.

2. Böger RH, Skamira C, Bode-Böger SM, Brabant G, von zur Muhlen A: Nitric oxide may mediate the hemodynamic effects of recombinant growth hormone in patients with acquired growth hormone deficiency. J Clin Invest 1996, 98:2706-27I3.

3. Khan AS, Sane DS, Wannenburg T, Sonntag WE: Growth hormone, insulin-like growth factor-I and the aging cardiovascular system. Cardiovasc Res 2002, 54:25-35.

4. McCallum RW, Petrie JR, Dominiczak A, Connell MC: Growth hormone deficiency and vascular risk. Clin Endocrinol 2002, 57:II-24.

5. Saccá L, Cittadini A, Fazio S: Growth hormone and the heart. Endocrine Reviews 1994, I 5:555-573.

6. Caidahl K, Edén S, Bengtsson B: Cardiovascular and renal effects of growth hormone. Clin Endocrinol (Oxf) 1994, 40(3):393-400.

7. Evans LM, Davies JS, Anderson RA, Ellis GR, Jackson SK, Lewis MJ, Frenneaux MP, Rees A, Scanlon MF: The effect of GH replacement therapy on endothelial function and oxidative stress in adult growth hormone deficiency. Eur J Endocrinol 2000, I 42:254-262.

8. László FA, Csernay L, Kocsis J: Effects of hypophysectomy on haemodynamic changes induced by administration of oestrone + vasopressin. Res exp Med 1974, 163:219-227.

9. Shen YT, Wiedmann RT, Lynch J], Grossman W, Johnson RG: GH replacement fails to improve ventricular function in hypophysectomized rats with myocardial infarction. Am J Physiol 1996, 271:HI721-HI727.

10. Gustafsson H, Wickman Tordby A, Brandin L, Hedin L, Jonsdottir IH: The interactive effects of growth hormone and oestrogen on vascular responses in hypophysectomized female rats. Eur J Endo 2002, I 46:267-274.

II. Rossoni G, Locatelli V, De GCV, Torsello A, Schweiger F, Boghen M, Nilsson M, Bernareggi M, Muller EE, Berti F: Growth hormone and hexarelin prevent endothelial vasodilator dysfunction in aortic rings of the hypophysectomized rat. J Cardiovasc Pharmacol 1999, 34:454-460.

12. Wickman A, Jonsdottir IH, Bergstrom G, Hedin L: GH and IGF-I regulate the expression of endothelial nitric oxide synthase (eNOS) in cardiovascular tissues of hypophysectomized female rats. Eur J Endocrinol 2002, I47:523-533.

13. Folkow B, Isaksson OGP, Karlström G, Lever AF, Nordlander M: Trophic effects of hypophyseal hormones on resistance vessels and the heart in normotensive and renal hypertensive rats. Acta Physiologica Scandinavica 1992, I44:291-306.

14. Napoli R, Guardasole V, Angelini V, D'Amico F, Zarra E, Matarazzo $M$, Sacca $L$ : Acute effects of growth hormone on vascular function in human subjects. J Clin Endocrinol Metab 2003, 88:2817-2820.

15. Thum T, Tsikas D, Frölich JC, Borlak J: Growth hormone induces eNOS expression and nitric oxide release in a cultured human endothelial cell line. FEBS Letters 2003, 555:567-57I.

16. Honeyman TW, Goodman HM, Fray JCS: The effects of growth hormone on blood pressure and renin secretion in hypophysectomized rats. Endocrinology 1983, I I 2:1613-1617.

17. Moller J, Jorgensen JO, Moller N, Hansen KW, Pedersen EB, Christiansen JS: Expansion of extracellular volume and suppression of atrial natriuretic peptide after growth hormone administration in normal man. J Clin Endocrinol Metab I991, 72:768-772.

18. Hoffman DM, Crampton L, Sernia C, Nguyen TV, Ho KKY: Shortterm growth hormone (GH) treatment of GH-deficient adults increases body sodium and extracellular water, but not blood pressure. J Clin Endocrinol Metab I996, 8 I : I I23-I I 28.

19. Bohlooy-Y M, Carlsson L, Olsson B, Gustafsson H, Andersson IJL, Törnell J, Bergström G: Vascular function and blood pressure in growth hormone transgenenic mice. Endocrinology 2001, 142:331 7-3323.

20. Dilley RJ, Schwartz SM: Vascular remodeling in the growth hormone transgenic mouse. Circulation Research 1989, 65:I233-I 240.

21. Fielder PJ, Mortensen DL, Mallet P, Carlsson B, Baxter RC, Clark R: Differential long-term effects of insulin-like growth factor-I (IGF-I), growth hormone (GH), and IGF-I plus GH on body growth and IGF-I binding proteins in hypophysectomized rats. Endocrinology 1996, 137:1913-1920. 
22. Sakuma I, Togashi H, Yoshioka M, Saito H, Yanagida M, Tamura M, Kobayashi T, Yasuda H, Gross SS, Levi R: NG-methyl-L-arginine, an inhibitor of L-arginine-derived nitric oxide synthesis, stimulates renal sympathetic nerve activity in vivo. A role for nitric oxide in the central regulation of sympathetic tone? Circ Res 1992, 70:607-6II.

23. Sverrisdottir YB, Elam M, Herlitz H, Bengtsson BA, Johannsson G: Intense sympathetic nerve activity in adults with hypopituitarism and untreated growth hormone deficiency. J Clin Endocrinol Metab 1998, 83: | 88|-|885.

24. Leong KS, Mann P, Wallymahmed M, MacFarlane IA, Wilding JP: Influence of growth hormone replacement on heart rate variability in adults with growth hormone deficiency. Clin Endocrinol 2001, 54:819-826.

25. Evans LM, Davies JS, Goodfellow J, Rees JA, Scanlon MF: Endothelial dysfunction in hypopituitary adults with growth hormone deficiency. Clin Endocrinol (Oxf) 1999, 50:457-464.

26. Jayachandran M, Hayashi T, Sumi D, Thakur NK, Kano H, Ignarro LJ, Iguchi $A$ : Up-regulation of endothelial nitric oxide synthase through beta(2)- adrenergic receptor--the role of a betablocker with NO-releasing action. Biochem Biophys Res Commun 200I, 280:589-594.

27. Wennmalm A, Benthin G, Edlund A, Jungersten L, Kieler-Jensen N, Lundin S, Westfelt UN, Petersson AS, Waagstein F: Metabolism and excretion of nitric oxide in humans. An experimental and clinical study. Circ Res 1993, 73:| | 21-II27.

Publish with Biomed Central and every scientist can read your work free of charge

"BioMed Central will be the most significant development for disseminating the results of biomedical research in our lifetime. "

Sir Paul Nurse, Cancer Research UK

Your research papers will be:

- available free of charge to the entire biomedical community

- peer reviewed and published immediately upon acceptance

- cited in PubMed and archived on PubMed Central

- yours - you keep the copyright

Submit your manuscript here:

http://www.biomedcentral.com/info/publishing_adv.asp
BioMedcentral 